INTERNATIONAL DESIGN CONFERENCE - DESIGN 2018

https://doi.org/10.21278/idc.2018.0249

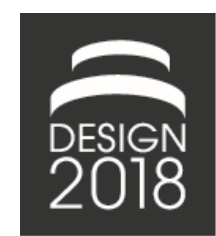

\title{
AN ASSESSMENT OF METHODS TO SUPPORT THE DESIGN OF FUTURE ROBUST MODULAR PRODUCT ARCHITECTURES
}

\author{
E. Greve and D. Krause
}

\begin{abstract}
Modular product architectures enable not only a trade-off between the external variety demanded by the customer and the cost-causing internal variety, but also facilitate the ability to react on future requirement changes with less effort. This work concentrates on the investigation of design support, which address both objectives at once. For this purpose relevant criteria for a successful design of the so called future robust modular product architectures are derived and used to gain and evaluate the existing design methods. The results are used to describe the further research focus.
\end{abstract}

Keywords: robust design, modularisation, product architecture, design for $x(D f X)$, integrated product development

\section{Introduction and research object}

Remaining competitive, companies continuously need to manage the increasing variety of products demanded by the customers. To respond on that need, companies try to diversify their product portfolio and create different product variants based on the individual customer requirements. That business strategy results in an increase of the internal variety as well as the complexity, which likely lead to increasing lead times and higher costs in all domains of a company (Krause and Gebhardt, 2018). To avoid that increase in complexity, but keeping the external variety of the demanded products as high as possible, companies are using modular product architectures (Otto et al., 2013). The development of modular product architectures (mPA) can be supported by numerous methods out of literature, e.g., Modular Function Deployment by Erixon (1998), Structural Complexity Management by Lindemann et al. (2009) or the Integrated PKT-Approach by Krause et al. (2014). By applying such product based approaches, a product architecture is designed, whose initial development and implementation takes a lot of time and whose adjustment results in higher costs and less turnover. Due to that fact, the use of $\mathrm{mPAs}$ calls for lifespans which are as long as possible to amortize the initial effort.

In contrast to that, the global trends of an interconnecting world, technological convergences or digitalization counteract that demand for long lasting lifespans, as they cause higher frequencies of influencing changes (f.e. technological steps, new competitors or markets, changing buying behaviour) for the product requirements and, thus, for the whole company (Fink and Siebe, 2016). To meet these challenges of uncertain requirements, designers try to estimate the future, f.e. by using several forecasts methods. The ensuing estimated changes of the external product variety need to be transferred on the product architecture by identifying parts, which will likely not change over a certain period of time. Using also modularization as a product architecture design approach, the robust parts will be clustered into functional groups and defined as a future robust platform. The other parts, which will likely change over time, are defined as flexible and are used to create the demanded external variety. 
Due to the fact, that both objectives (need for management of variety and ability to react on changing requirements) call for modular structured products, but use different design approaches, an investigation concerning the design support linking both objectives should be worked out. Modular product architectures aiming these two goals are in the following named as future robust (Figure 1).

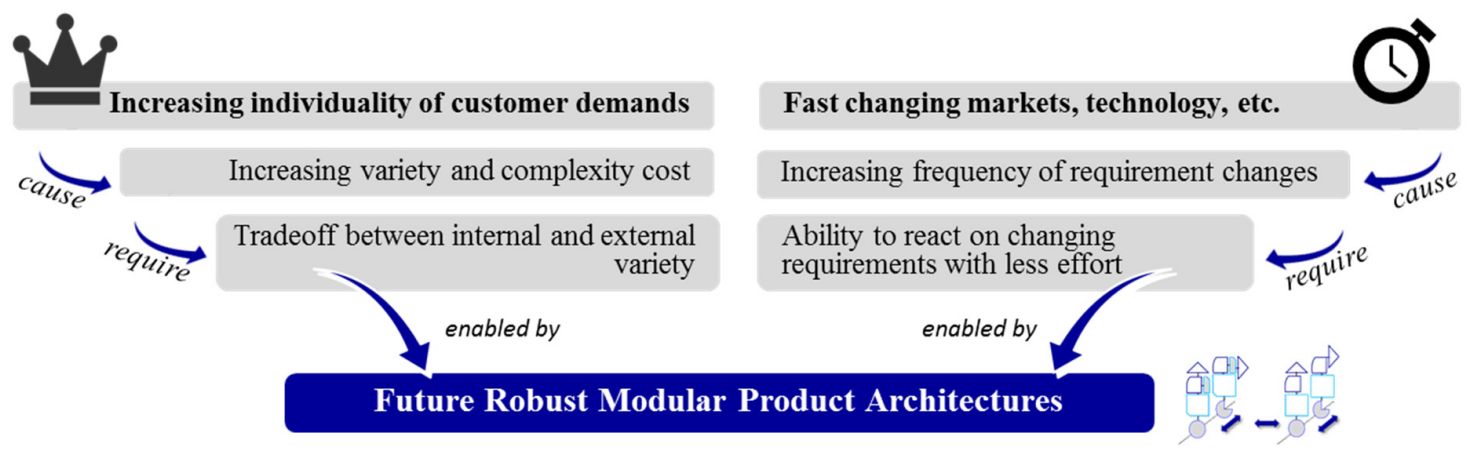

Figure 1. Objectives enabled by future robust modular product architectures

To investigate the existing support, an assessment based on relevant criteria should be worked out. For this purpose, at first the state of the art in modular product architecture design should be shown, whereupon the term of future robustness in context of $\mathrm{mPA}$ design is defined. Relevant criteria concerning the development of future robust mPA will be suggested in Section 3. For this, multiple iterative literature reviews and an empirical study will be conducted. Using the relevant criteria list, the existing methodical support in the design of future robust mPA will be presented and assessed. Derived from the results of the evaluation, the outcome of this work is the further research focus in the support for designing future robust $\mathrm{mPA}$.

\section{Background}

\subsection{Modular product architecture design}

In context of product development, a product architecture can be described as the allocation of the functions to the building blocks of the product (product structure) and the specification of the interfaces among interacting physical components (Ulrich and Eppinger, 2004). A modular design of a product architecture offers the possibility to maintain a high external product variety and to reduce the internal variety within the company. Hence, the associated complexity of corporate processes in the product development can be handled, reduced, or avoided (Krause et al., 2014). The term of modularity can be defined as a gradual property of a system of products rather than of a single product and is characterized by five basic attributes, namely communality (use of products in several products), combinability (use of modules for configuration of the product variants), function binding (1:1 or $\mathrm{n}: 1$ mapping between functions and modules), interface standardization (physical standardization of interfaces of modules) and decoupling (interaction and the binding among modules is weaker than the internal coupling of module components) (Salvador, 2007). These characteristics are themselves gradual parameters and determine in their entirety the overall modularity degree.

When developing a mPA, there is no ideal value for a modularity degree which indicates an optimal architecture design - it's rather the degree of finding an optimal trade-off between the advantages and disadvantages in context of the needs of all relevant stakeholders (designer, manufacturer, customer, etc.). Due to that fact, the methods supporting the design of mPA vary in their focus, too. Here the literature offers various methods, which can be classified into two different approaches - the technicalfunctional and the product-strategic perspective (Jiao et al., 2007). Applying the technical-functional approach, modules are basically deployed by the analysis of component coupling and functional terms. Relevant methods for that modularization approach are Design Structure Matrix (Pimmler and Eppinger, 1994), Structural Complexity Management (Lindemann, 2009) and Function modules (Pahl et al., 2007). The other perspective considers aspects from different product life phases and supports the design of a mPA to reduce the internal variety from strategical and organizational point of view. That is also 
essential, as one of the major advantages of this strategy - the derivation of a large number of standard modules - enables cost reduction with better utilization of economies of scale and learning curve results in all life stages, especially in procurement, manufacturing and assembly. For example, processes can be parallelized to develop different modules in parallel and to test or produce them separately (Krause et al., 2014). Erixon (1998) focused in his Modular Function Deployment the product-strategical perspective and assigned the advantages of all stages in module drivers, which are used to design an optimal mPA from the point of view of each life phase. Also Harlou and Mortensen (2006) address that view of modularization in their Product Family Masterplan. The Integrated PKT-approach for the development of modular product families (Krause et al., 2014) is an integrative method, which considers a harmonization of the different product-strategic potentials as well as a technical-functional perspective during the modularization (classification see Figure 2).

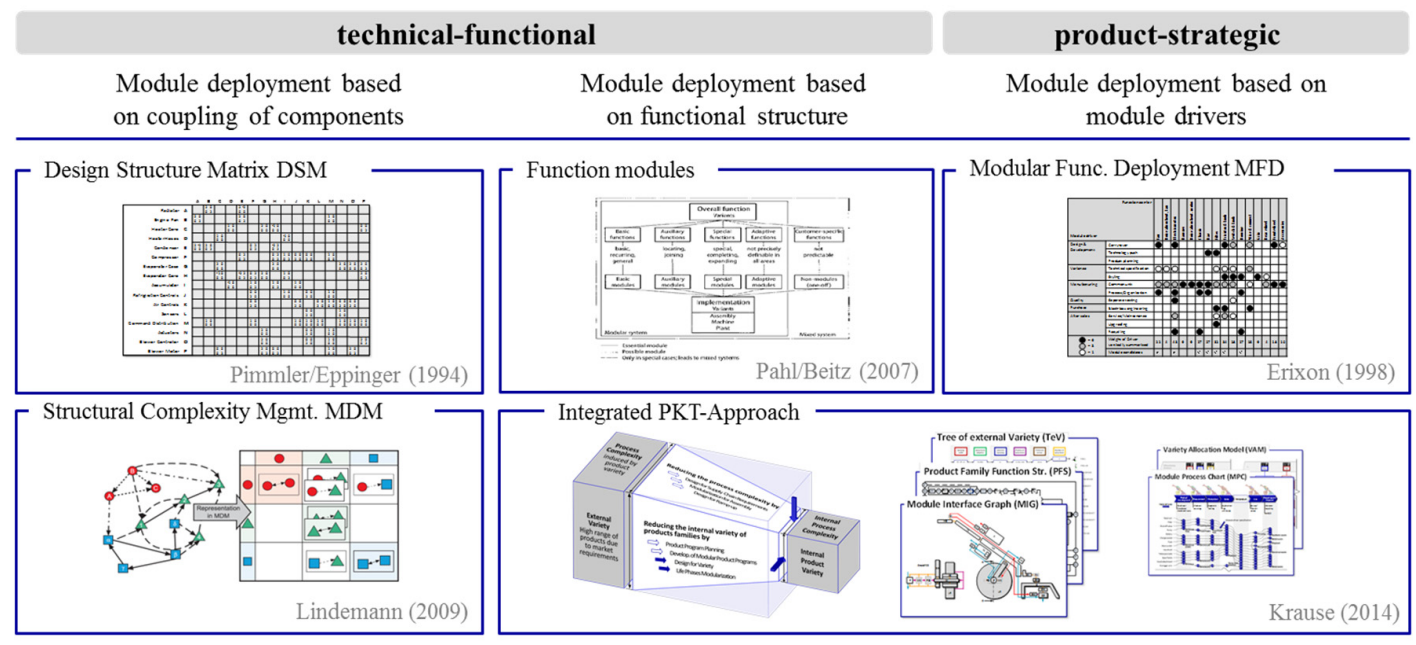

Figure 2. Classification of modularization methods

\subsection{Future robustness}

Not be confused with potential synonyms like hardness - which is part of other field of references (f.e. material science) - robustness can be described as an ability of a system, which provides a certain value despite dynamic changes in its immediate environment and without changing any parameters of the system (Saleh et al., 2009). A robust system is insensitive to any disturbance values (Fricke and Schulz, 2005) and absorbs unplanned changes as it always meets a certain set of requirements (Phadke, 1989).

Referred to the product architecture as the "system", robustness characterizes the elements of the architecture, which have invariant forms, features or functions and require no adjustments despite of unwanted changes due to dynamic and temporal factors of influence (Simpson et al., 1998). Such influencing factors can be anything which leverages the company in the future, f.e. changing buying behaviour, markets, statutes, social systems or continuous progression of technologies (Guiltinan, 1999). Robust elements can be for example those elements of the product architecture, which enable an established principle of operation and are necessary to ensure the function of the product.

In context of a variant product environment, the definition of robust elements by itself doesn't enable the company to diversify their product portfolio, as the value of robust components lies in the communal usage across different product variants (Siddique et al., 1998). Thus, a future robust product architecture also needs elements generating diversifying features, which are demanded at a certain point of time. That diversification aspect can be addressed by the characteristic of flexibility, which describes the ability of a system to modify the status quo due to external changes without any negative side effects and with little effort (Cardin, 2014). Flexible elements are for example design elements, which likely change over time due to social alterations. Robustness and, as a counterpart, flexibility are established aspects in the field of changeability (Fricke and Schulz, 2005).

In the context of this work, product architectures are assumed to be future robust, when they are designed by the objective of causing as less adjustment efforts and costs due to future changes as possible. As 
mentioned in the outset, modularization is the most efficient and used product architecture approach when future robustness should be enabled, which a lot of authors approved along multiple studies (comprehensive overview in Bauer, 2016). The common procedure in the design of future robust mPA out of literature is characterized by encapsulating the identified robust parts which are insensitive to noise factors and variation into a common range in order to receive scale effects by reuse these parts over a certain period of time.

\section{Methodical support for the design of future robust mPA}

\subsection{Research design}

For the purpose of giving a complete overview of the existing support for the design of future robust $\mathrm{mPA}$, the deployed research design is presented in this section. The procedure is separated into four steps, which can be seen in Figure 3.

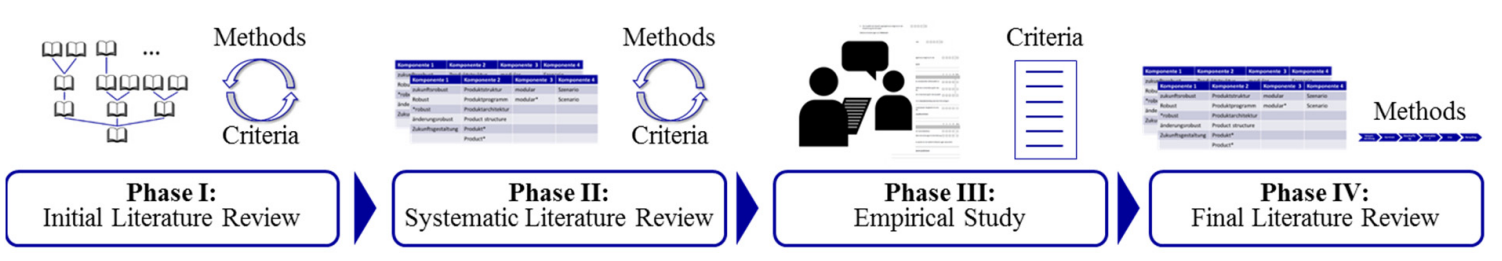

Figure 3. Procedure during the data base collection

At first an initial literature study, based on a reference snowball system, is executed. During that review, the focus lays on methods to support the design of $\mathrm{mPA}$, which especially aim either variety reduction and/or future oriented aspects. The objective of this first stage is to understand the general procedure in the design of mPA related to variety and future robustness and to gain an initial data base of relevant approaches in that field of application. The characteristic of this phase is determined by iteration, which means that the criteria gained out of methods are ongoing used to find another method and vice versa. After a certain method pool is analysed and initial relevant criteria for the design of future robust mPA are derived, the basic understanding in this topic is used to conduct a second, deeper literature review. For that, a systematic keyword search is done, where also synonyms related to the topic are utilized. The most relevant fields of interest during the research can be seen in Figure 4.

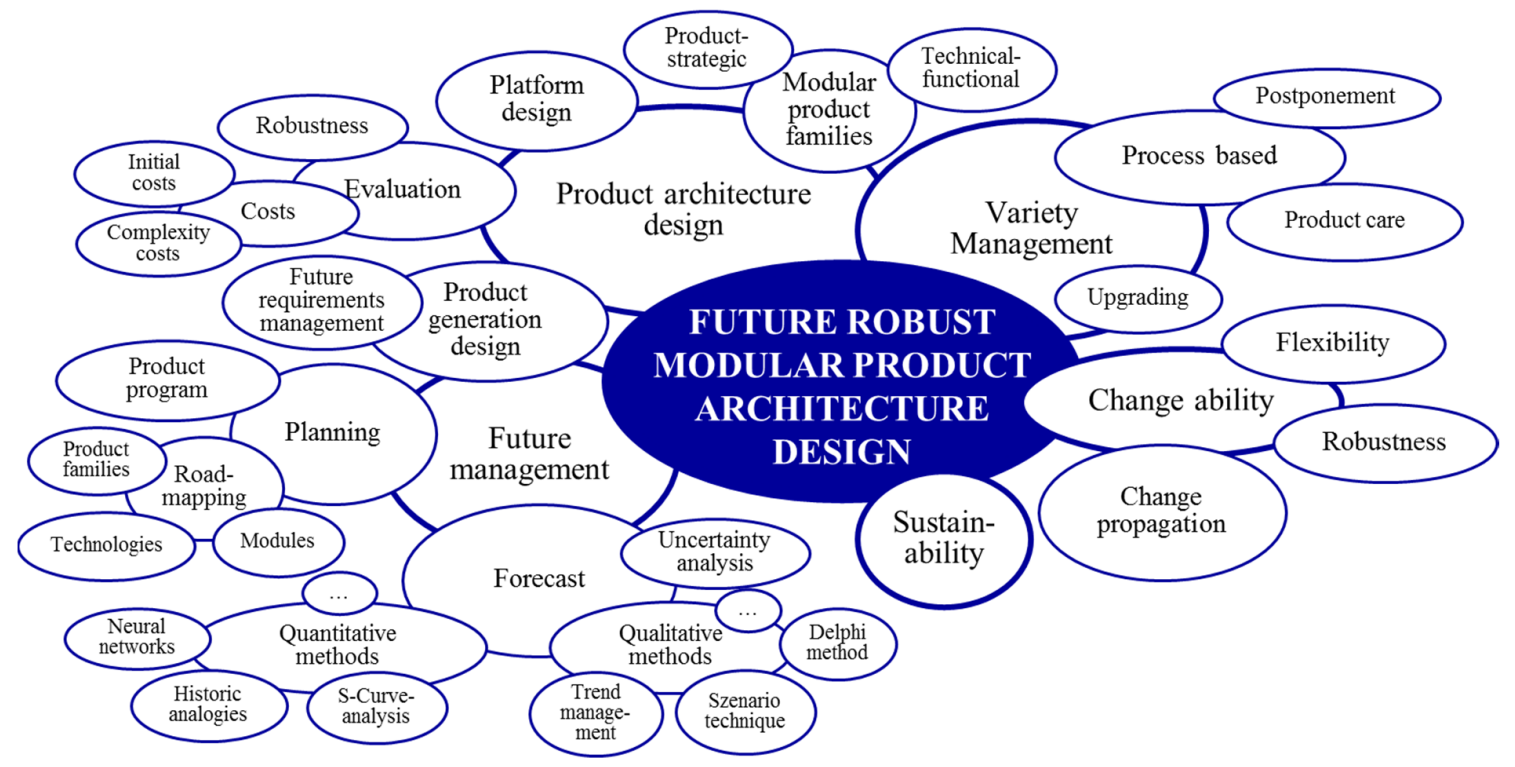

Figure 4. Relevant fields of interest regarding future robust mPA design 
In this second phase the method pool can be complemented and further criteria repetitively be derived. In the next step, the criteria list gained out of literature is discussed, evaluated and extended by an interview study with experts who have many years of experience in the execution of modularization projects in industry. For that purpose, only employees out of companies working in highly variant product environments are surveyed. To ensure the experience in future robust design, executives out of three companies who currently working in a group project that aims the design of future robust $\mathrm{mPA}$ are interviewed. Here a certain degree of familiarity with the topic (the project last more than one year) can be assumed and used to increase the validity of the statements.

The criteria gained out of this step are compared and added to the list based on literature findings. That updated list is used for a final systematic literature review to ensure, that all relevant methods are gained.

\subsection{Relevant criteria}

After applying the presented research design, overall 16 relevant criteria for designing an optimal future robust $\mathrm{mPA}$ could be worked out. For the part of $\mathrm{mPA}$ design especially out of variety concerning aspects, a former comprehensive study executed by Krause and Ripperda (2013) could be encountered. The authors worked out 13 criteria for the design of an optimal modular product family, which were identified out of a broad literature review and along multiple modularization projects. Due to its connection to the present term, nine of the criteria have been adapted to the current criteria list.

For the aspect of the future robustness, the literature doesn't offer such a comprehensive study. Therefore the introduced research design has been applied. After the initial collected methods and criteria were analysed, it could be figured out, that a lot of criteria overlap to the criteria gained by Krause and Ripperda (2013). That fact can be affiliate to the circumstance, that these are objective independent criteria for modular product architecture design. Despite this, three future specific criteria could be verified in the end of the second phase. The overall criteria list including variety and future robust aspects were discussed with experts out of industry. Here two more criteria could be identified and added to the final list. The gained 16 criteria can be seen in Figure 5 and are briefly described hereafter.

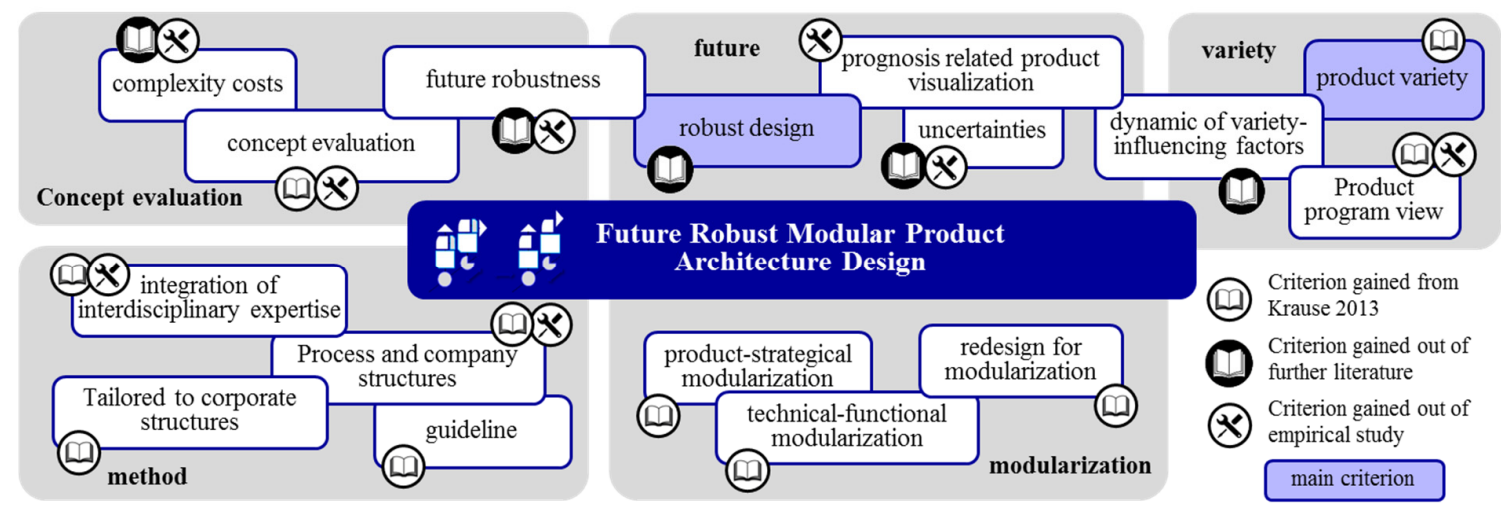

Figure 5. Classification of the gained criteria for the design of future robust $\mathrm{mPA}$

The main objectives for the design of future robust $\mathrm{mPA}$ are the consideration of product variety and robust design. Product variety means that the design method can not only be applied on a single product, but also takes product variants or the whole product family into account (Krause and Ripperda, 2013). Robust design indicates, that product architectures are designed concerning the objective to cause less adjustment effort due to future changes. To assume, which elements of the product architecture will likely/not likely change over time, also the dynamic of variety-influencing factors must be considered. For this purpose the literature offers different qualitative and quantitative 
forecast methods, such as scenario technique by Gausemeier (2009) or scenario management by Fink and Siebe (2016). Essential in that context is, that the changes related to the customer relevant requirements must be the focus of the used forecast. Due to the fact, that a prognosis is always linked with probabilities, the uncertainties of the estimated changes must also be considered during the design of the product architecture. Because the estimation of future changes is often very fuzzy, the holistic impacts cannot be transferred directly into the product architecture. Due to the fact, that those impacts often occur at a very high level (f.e. mobility), the view on the whole product program is demanded. To enable the design of the $\mathrm{mPA}$, the estimated external and internal variety-related changes must be mapped to the product architecture. For this purpose a prognosis related product visualization is needed. That criterion qualifies, whether the method works with an illustration of the product variants (e.g. sketched geometry, cad drawing, etc.) and visualizes the projected changes to the product architecture. The recognized support results out of the conducted empirical study and complements Krause's and Ripperda's criterion of product related visualization, as it is included in this new criterion. Next to the design support itself, it has been proven that visualization tools support the interdisciplinary application, which Krause and Ripperda claim as necessary for a successful modularization project. That is why the integration of interdisciplinary expertise is also adapted to the current problem. As mentioned in Section 2, a mPA must always be designed considering both, a technical-functional as well as a product-strategic modularization. The redesign for modularization refers to the redesign of the product. This criterion is specified as a grouping of components into modules without design changes doesn't count as redesign. Further the methodical work should be supported by a guideline, which offers an accurate description of the several steps of the approach. That criterion could be confirmed by the empirical study. The criterion tailored to corporate situation describes the possibility of adjustment of the method to the special needs of a company. This criterion could be especially measured in the range of industries and the number of successful applications in case studies (Krause and Ripperda, 2013). The treatment of the organizational structure and supply chain management is considered in process and company structures. One of the most important criteria for an optimal approach supporting the design of mPA is the estimation and consideration of costs. Here the so called complexity costs, caused by variety in products and processes, are in focus. These types of costs generate a large amount of hidden costs in companies which offer a high degree of product variety. The estimation of complexity costs is heavily linked to the criteria of the consideration of product-strategic modularization, as the variety-induced complexity costs occur along the entire product life-cycle (Rathnow, 1993). Due to this, during the assessment in the following section there will be a special focus on the complexity costs. The last criterion is the concept evaluation. This means that the optimized product should be compared with the starting product. That comparison is an established methodical action to support the decision for the final modular product concept. Due to the objective to design a future robust $\mathrm{mPA}$, one of the evaluation criteria must be future robustness. That characteristic describes how much adjustment efforts and associated costs will occur due to a certain future change.

\subsection{Characterization and assessment}

Conducting a closing literature review based on the gained criteria, overall 12 relevant methods could be figured out. These approaches are assessed by the author using the criteria for an optimal support for the design of future robust mPA. Table 1 shows the overview of the 12 approaches, which are ordered by the year of publication.

The lines depict the selected approaches which contribute to the design of future robust mPA. The columns list the criteria shown and described in Section 3.2. Each criterion is classified into the three categories: not/weakly considered, partially considered and mainly considered. 
Table 1. Assessment of the methodologies

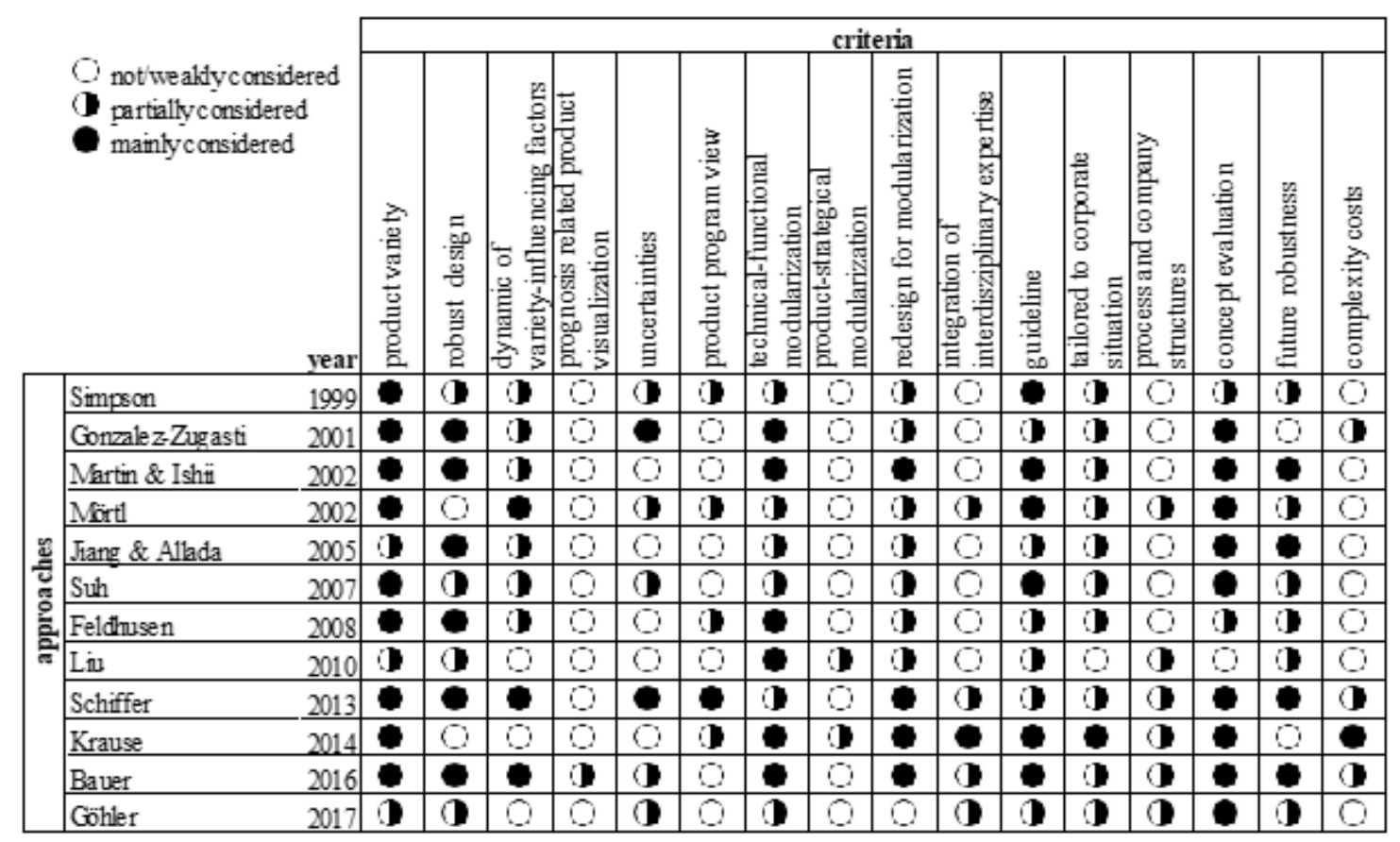

Product Platform Concept Exploration Method - Simpson: In the Product Platform Concept Exploration Method (PPCEM) by Simpson et al. (1999) the development of scalable product platforms and their corresponding product families is realized. After identifying relevant requirements and dynamic control factors gained out of market analysis, the boundaries of the scale variables are determined. The definition of the needed similarities and variations is based on a mathematical model and uncertainties are considered in a sense by consideration of the relevant control factors. By applying a decision support model, the robust and scalable product platform finally can be designed.

Assessing Value in Platformed Product Family Design - Gonzalez-Zugasti: Gonzalez-Zugasti et al. (2001) enable the designer to create alternative product platforms out of a technical-functional perspective and supports their selection by applying a mathematical approach. Beside the value for the costs of each platform, also factors for uncertainties gained out of a future analysis are consulted during the decision. Complexity costs are neglected at all in the assessing method.

Design for Variety - Martin \& Ishii: Based on an assessment of the technical coupling strength of components and a consideration of planned future changes, Martin and Ishii (2002) introduce in Design for Variety (DfV) an approach for the design of a long-term robust product platform. For the assessment, the authors define two indices. The Generational Variety Index (GVI) evaluates the redesign effort of components due to future requirement changes and the Coupling Index (CI) quantifies the coupling among parts and expresses the sensitivities of components to changes in the connection flow (materials, energy, etc.). Using both indices, the future robust components can be identified and consolidated into a platform. That platform is assumed to be future robust and can be used among following product generations. For the rearrangement, the authors neglects product-strategical aspects and don't consider the complexity costs.

Design management for long-life and upgrading-oriented products - Mörtl: In that management oriented approach, Mörtl (2002) introduces a holistic process to design products with extended lifespans. Here the focus lays more on the identification of flexible parts then on future robust elements. To enable the enlargement, future product requirements are estimated and mapped to the product architecture already in the early design stage. While the product itself is developed as usual, the modules which enable future features are designed in a parallel design process. At a certain point when the use phase of the initial product is assumed to expire, the separately designed modules can be used for an upgrading and, thus, for an enabling of additional use phases. 
Robust Modular Product Family Design Methodology - Jiang \& Allada: The objective of the Robust Modular Product Family Design Methodology by Jiang and Allada (2005) is to identify the optimal control factors for assessing the highest possible profit-oriented robustness of the product architecture by using a modified Taguchi method. The authors use present initial customer requirements and their estimated changes over time to define the lifespan in which the product architecture enables the optimal turnover within a defined framework. When the boundary is undercut, conceptual changes are required. The application of the method enables the determination of variant modules which have profit-oriented future robustness - the specific design of the product architecture itself is not supported.

Flexible Platform Design Process - Suh: In Flexible Platform Design Process a design approach is given, which lays focus on the identification of potential flexibility within the product architecture (Suh et al., 2007). After determining target market segments and external uncertainties which influence the desired product variants, the affected elements in the product architecture are identified and defined as flexible. The needed platform flexibility is represented by band widths in which the assumed features are ranged. During the assessment of the designed concept alternatives, just initial design costs are considered.

Multi-life products - Feldhusen: Feldhusen (2008) developed in his concept of Multi-life products a product core, which aims the saving of physical and time-consuming resources across sequential market cycles and their associated product generations. For the design of the robust product platform, at first the constant as well as the time invariant product requirements are derived by generating scenarios for different market cycles. By the use of a requirement-function-matrix, the robust and flexible functions can be identified and linked to the product architecture. The definite arrangement of the physical structure is not considered.

Top-Down Platform and Product Family Design - Liu: Liu et al. (2010) design a product platform with the objective to enable scale effects due to a maximum of product and process commonalities. Based on a market analysis, the needed product variants and their requirements are derived, although the dynamic aspect is not entirely considered. After the product architecture is created by applying the technical-functional modularization heuristics according to Stone et al. (2000), the gained product architecture is optimized with regards to enable a maximum of physical as well as production process oriented commonality.

Scenario-based Product Development - Schiffer: In the Scenario-based Product Development by Schiffer (2013) the scenario technique by Gausemeier (2009) is used to identify key factors, which have major effects on the external variety the company has to offer in the future. By deducing projections out of the key factors and estimating their probability of occurrence, customer relevant requirements which directly influence the product architecture can be derived. After the characteristics of the customer relevant requirements and their probabilities are defined, the product architecture can be designed. For this purpose the requirements are linked to the physical components. That process is supported by a holistic model as well as abstract design rules based on effect analysis and gained out of technicalfunctional modularization perspective. Complexity costs are rudimentarily considered during the final assessment of the designed concept alternatives by applying a process cost calculation.

Integrated PKT-approach to develop modular product families - Krause: The approach by Krause (2014) aims the design of modular product families and combines the product-oriented view with the process-oriented view of product variety. The approach consists of several method units, which can be arranged depending on the corporate needs. With regards to the gained criteria of this research, especially the units Design for Variety, Life Phases Modularization and Complexity Cost Management are of peculiar interest. In Design for Variety the variety-influencing factors are investigated and used to design a variety-oriented product architecture, which addresses only the required needs of the customers. The dynamics of the factors are not considered and the developed product-related visualization just depicts the variety, but not prognosis-related aspects. The unit Life Phases Modularization considers both, the technical-functional as well as the product-strategic aspects during the modularization. The used module drivers are treated as time invariant, so the requirement of dynamics and future robustness is neglected at all. In Complexity Cost Management by Ripperda and Krause (2017) a cost evaluation of the gained modular product architecture alternatives is introduced. 
Here not only initial development costs, but also life cycle costs and total costs of ownership are considered.

Planning and Development of change-robust Platform Architectures - Bauer: The methodical approach developed by Bauer (2016) aims for the design of a robust product platform with an integrated consideration of aspects out of the early design stage and care processes during the use phase. After analysing the existing product architecture, the future variety-influencing changes out of an external perspective are estimated by conducting a qualitative as well as a quantitative prognosis. The effects of the changes are transferred to the product functions and further to the product architecture. Using the characteristic of changing ability, flexible and robust domains in the product architecture are identified. By applying a DSM-based technical-functional modularization approach, the components are clustered into modules, which likely have the same robust characteristics. The author also supports the care process, as he also plans the use phase in the early design stages. Here also complexity costs concerning the use of different product variants are considered. Other life cycle phases (e.g. manufacturing) of the product are neglected and not considered during the complexity cost calculation.

Metric-driven Robust Design - Göhler: Göhler (2017) concentrates on a metric-based quantification of robustness and introduces the tool Variety Management Framework (VMF), which supports a holistic robust product design. By applying the VMF tool, the relations of different degrees of fidelity, structural and functional robustness are analysed and quantified concerning the robustness throughout the design stage. Here also production and marketing relevant terms are considered.

\section{Implications for the design of future robust mPA}

The assessment of the design methods has shown, that there exists some essential lacks when the objectives of future robustness and variety-alignment should be linked together in modular product architecture design.

One of the most important missing links in the existing methodical support for the design of future robust $\mathrm{mPA}$ is the negligence of product-strategical aspects during the consideration of future changes as well as during the modularization itself. The existing approaches concentrate mostly on a technicalfunctional modularization by estimating future changes and identifying these components which will not likely change over time. In most of the gained methods, these types of components are clustered together and represent the product platform in order to gain benefits of scale effects due to component commonality. That describes just a designer's and technical-functional point of view - other life phases with different requirements on the future robust platform are not considered. As mentioned in sector 2, the consideration of product-strategical aspects must be observed in addition to the technical-functional modularization to address the best trade-off of the advantages of the mPA. That is currently enabled only by the Integrated PKT-approach Krause et al. (2014).

Further the changes, which cause the future variety are only estimated by consideration of external factors, like future market segment coverage or technological innovations. That only affects the sales point of view, which is - in fact - essential to remain competitive. But it is proven, that also a large part of economic advantages can be tapped due to the use of mPA in other product life phases such as manufacturing (Krause, 2014; Bauer, 2016). Existing methods in that field of application consider that fact by defining module drivers out of different product life phase perspectives and cluster the components not just out of a technical-functional point of view. That those drivers underlie dynamics too (e.g. changing manufacturing technologies, material prices, relocation or impacts of digitalization in general on the company) is neglected at all. Thus, the dynamics of module drivers out of different life phases must be integrated in further development of support for the design of future robust mPA.

Besides the missing of dynamical product-strategical aspects, the demanded prognosis related product visualization is missing at all in the existing approaches. Here further research activities should focus on the illustration of the dynamics of customer relevant characteristics and their link to the product architecture. To gain those time invariant customer relevant properties, most of the evaluated approaches applied some kind of forecast methods. Due to the fact, that such methods generate often just holistic results and not the demanded customer relevant characteristics, the effects of the forecasts must be at first transferred to the overall product program of the company and then - on the second level - to the product variants with its characteristics. The investigated methods out of the literature try to assign the 
forecast result directly to the product architecture, which is often too fuzzy, defective and nontransparent. Thereby the consideration of uncertainties is essential too, as it is important for the evaluation and for the decision support of the later gained product architecture alternatives.

Another relevant shortcoming can be identified during the evaluation of the gained future robust mPA alternatives and, hence, during the overall decision of the final product architecture concept. Depending on the respective definition of the future robustness term, the existing methods concentrate mostly on the assessment of such in context of long market coverage as possible. A monetary evaluation is merely done by an estimation of the initial effort for the development and production costs of the mPA. However, the more crucial complexity costs caused by indirect factors in all stages of the product life cycle (e.g. warehousing costs, long delivery times, extensive documentation and maintenance) are not considered in their entirety. Only the Complexity Cost Management by Ripperda and Krause (2017) within the Integrated PKT-approach addresses these types of costs, but neglects their dynamics in the product architecture design. Bauer (2016) considers that aspect in his method, but refers just on costs which are caused by change-induced product variants and not by aspects out of other product life phases. Thus, the consideration of complexity costs during the design of future robust mPA can be further identified as essential need for research. An overview about the main shortcomings is depicted in Figure 6.

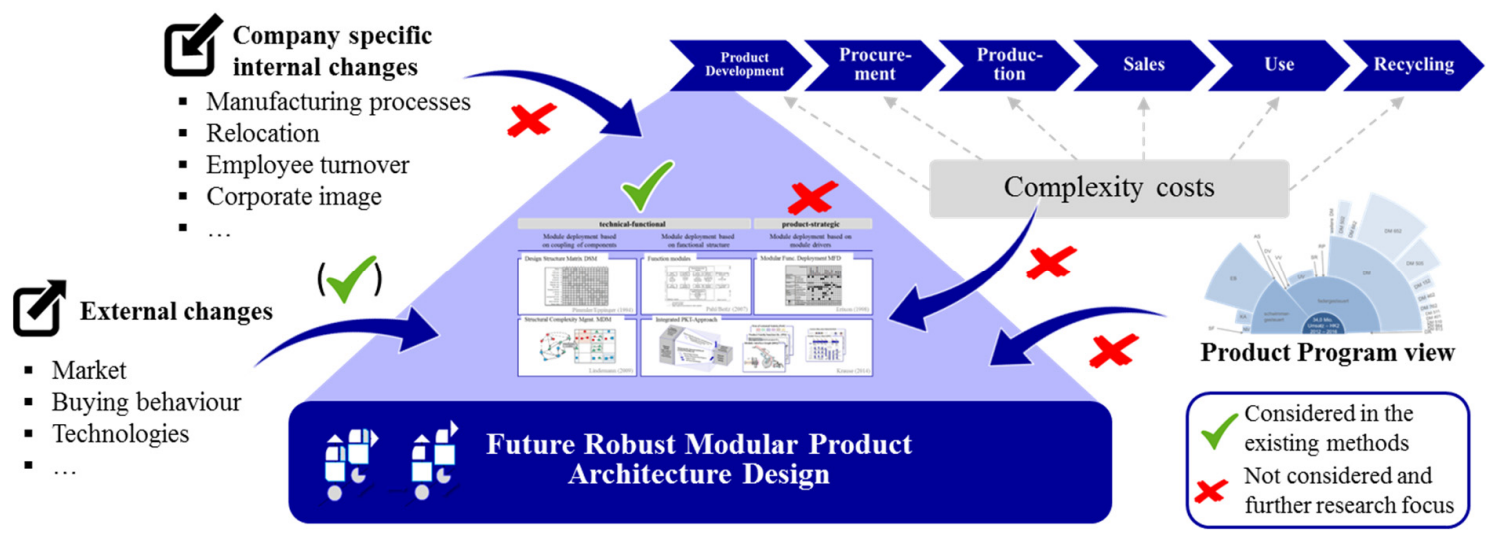

Figure 6. Further research focus in the design of future robust mPA

In the next step an overall framework for the design of future robust mPA including the findings out of that work must be deployed. Here especially the integration of product-strategical aspects and their dynamics must be considered during the future robust module design. For the determination of the requirement changes due to different life phase aspects, a further literature review and empirical study should be worked out. For the development of the named visualization tool at first the detailed requirements must be arranged. For the integration of the complexity costs during the evaluation, the calculation method developed by Ripperda and Krause (2017) can be used and extended regarding the issue of future robustness.

\section{Conclusion}

Modular product architecture design enables not only a trade-off between the demanded external variety and the cost-causing internal variety, but also facilitate the ability to react on future requirement changes by encapsulating components into modules, which will not likely change over time. The association of both competitive relevant objectives is signed in this work as future robust - a characteristic of a mPA, which enables the derivation of future product variants with less effort and cost as possible. Due to the importance of this type of product architecture, the support for the design of future robust mPA has been investigated in this work. For that purpose firstly relevant criteria for an optimal design were deduced out of a literature review as well as an empirical study. Based on the criteria, the existing methodical approaches in that field of application were subsequently gained out of literature and assessed by an evaluation of the relevant criteria. The derived shortcomings represent the outcome of this work. Here especially the lack of an integration of product-strategical aspects (during the estimation of future 
changes and during the creation of the future robust modules) in the existing methods could be observed. The need for a visualization tool (which connects the customer relevant requirement changes to the product architecture) as well as the missing consideration of a future oriented complexity cost calculation is also a criterion which is not sufficiently fulfilled in the existing methodical approaches. Those shortcomings should be in focus of further research in the field of future robust modular product architecture design.

\section{Acknowledgment}

The author wishes to thank the German federal Ministry of Education and Research for founding this work and all participants of the interviews for their contribution to this research.

\section{References}

Bauer, W. (2016), Planung und Entwicklung änderungsrobuster Plattformarchitekturen, PhD thesis, Technische Universität München.

Cardin, M.-A. (2014), "Enabling Flexibility in Engineering Systems: A Taxonomy of Procedures and a Design Framework", Journal of Mechanical Design, Vol. 136 No. 1, pp. 1-14. https://doi.org/10.1115/1.4025704

Erixon, G. (1998), Modular Function Deployment: A Method for Product Modularisation, PhD thesis, The Royal Institute of Technology.

Feldhusen, J. and Gebhardt, B. (2008), Product Lifecycle Management für die Praxis: Ein Leitfaden zur modularen Einführung, Umsetzung und Anwendung, Springer, Berlin. https://doi.org/10.1007/978-3-540-34009-6

Fink, A. and Siebe, A. (2016), Szenario Management: Von strategischem Vorausdenken zu zukunftsrobusten Entscheidungen, Campus Verlag, Frankfurt.

Fricke, E. and Schulz, A.P. (2005), "Design for Changeability (DFC): Principles to Enable Changes in Systems Throughout Their Entire Lifecycle”, Systems Engineering, Vol. 8 No. 4, pp. 342-359. https://doi.org/10.1002/sys.20039

Gausemeier, J., Plass, C. and Wenzelmann, C. (2009), Zukunftsorientierte Unternehmensgestaltung: Strategien, Geschäftsprozesse und IT-Systeme für die Produktion von Morgen, Hanser Verlag, München.

Göhler, S.M. (2017), Metric-driven Robust Design - Robustness Quantification of Complex Engineering Systems, $\mathrm{PhD}$ thesis, Technical University of Denmark.

Gonzalez-Zugasti, J.P., Otto, K.N. and Baker, J.D. (2001), "Assessing value in platformed product family design", Research in Engineering Design, Vol. 13 No. 1, pp. 30-41. https://doi.org/10.1007/s001630100001

Guiltinan, J.P. (1999), "Launch strategy, launch tactics, and demand outcomes", Journal of Product Innovation Management, Vol. 16 No. 6, pp. 509-529. https://doi.org/10.1111/1540-5885.1660027

Harlou, U. (2006), Developing product families based on architectures, PhD thesis, Technical University of Denmark.

Jiang, L. and Allada, V. (2005), "Robust modular product family design using a modified Taguchi method", Journal of Engineering Design, Vol. 16 No. 5, pp. 443-458. https://doi.org/10.1080/09544820500287359

Jiao, J.R., Simpson, T.W. and Siddique, Z. (2007), "Product family design and platform-based product development: a state-of-the-art review", Journal of Intelligent Manufacturing, Vol. 18 No. 1, pp. 5-29. https://doi.org/10.1007/s10845-007-0003-2

Krause, D. and Ripperda, S. (2013), "An assessment of methodical approaches to support the development of modular product families", 19th International Conference on Engineering Design, Seoul, Korea, August 19 22, The Design Society, Glasgow, pp. 31-40.

Krause, D., Beckmann, G., Eilmus, S., Gebhardt, N., Jonas, H. and Rettberg, R. (2014), "Integrated Development of Modular Product Families: A Methods Toolkit”, In: Simpson, T.W., Jiao J., Siddique Z. and Hölttä-Otto K. (Ed.), Advances in product family and product platform design, Springer, New York, pp. 245-269. https://doi.org/10.1007/978-1-4614-7937-6_10

Krause, D. and Gebhardt, N. (2018), Methodische Entwicklung modularer Produktfamilien: Hohe Produktvielfalt beherrschbar entwickeln, Springer, Berlin. https://doi.org/10.1007/978-3-662-53040-5

Lindemann, U., Maurer, M. and Braun, T. (2009), Structural Complexity Management: an approach for the field of product design, Springer, Berlin. https://doi.org/10.1007/978-3-540-87889-6

Liu, Z., Wong, Y.S. and Lee, K.S. (2010), "Modularity analysis and commonality design: a framework for the topdown platform and product family design”, International Journal of Production Research, Vol. 48 No. 12, pp. 3657-3680. https://doi.org/10.1080/00207540902902598

Martin, M. and Ishii, K. (2002), "Design for Variety: developing standardized and modularized product platform architectures", Research in Engineering Design, Vol. 13, No. 4, pp. 213-235. https://doi.org/0.1007/s00163002-0020-2 
Mörtl, M. (2002), Entwicklungsmanagement für langlebige, upgradegerechte Produkte, PhD thesis, Technische Universität München.

Otto, K., Hölttä-Otto, K. and Simpson, T.W. (2013), "Linking 10 years of modular design research: alternative Methods and tool chain sequences to support product platform design", Proceedings of ASME IDETC/CIE, Portland, Oregon, USA, August 4-7, 2013, pp. V03BT03A035. https://doi.org/10.1115/DETC2013-12523

Pahl, G., Beitz, W., Feldhusen, J. and Grote K.-H. (2007), Engineering Design: A Systematic Approach, Springer, London.

Phadke, M.S. (1989), Quality engineering using robust design, Prentice Hall, Englewood Cliffs.

Pimmler, T.U. and Eppinger, S.D. (1994), "Integration Analysis of Product Decompositions", ASME International Design Engineering Technical Conferences, Minneapolis, USA, Alfred P. Sloan School of Management, Massachusetts Institute of Technology.

Rathnow, P.J. (1993), Integriertes Variantenmanagement: Bestimmung, Realisierung und Sicherung der Optimalen Produktvielfalt, Vandenhoeck \& Ruprecht, Göttingen, Germany.

Ripperda, S. and Krause, D. (2017), "Cost Effects of Modular Product Family Structures: Methods and Quantification of Impacts to Support Decision Making”, Journal of Mechanical Design, Vol. 139 No. 2. https://doi.org/10.1115/1.4035430

Saleh, J.H., Mark, G. and Jordan, N.C. (2009), "Flexibility: a multi-disciplinary literature review and a research agenda for designing flexible engineering systems", Journal of Engineering Design, Vol. 20 No. 3, pp. 307323. https://doi.org/10.1080/09544820701870813

Salvador, F. (2007), "Toward a Product System Modularity Construct. Literature Review and Reconceptualization”, IEEE Transactions on Engineering Management, Vol. 54 No. 2, pp. 219-240. http://dx.doi.org/10.1109/TEM.2007.893996

Schiffer, M.G. (2013), Szenariorobuste Produktarchitekturgestaltung, PhD thesis, Rheinisch-Westfälische Technische Hochschule Aachen.

Siddique, Z., Rosen, D.W. and Wang, N. (1998), "On the applicability of product variety design concepts to automotive platform commonality”, Proceedings of DETC'98 / ASME Design Engineering Technical Conferences, Atlanta, Georgia, September 13 - 16, 1998.

Simpson, T.W., Lautenschlager, U. and Mistree, F. (1998), "Toward Mass Customization in the Age of Information: The Case for Open Engineering Systems”, In: Read, W.H. and Porter, A. (Ed.), The Information Revolution: Present and Future, Ablex Publishing, Greenwich, USA.

Simpson, T.W., Maier, J.R.A. and Mistree, F. (1999), "A Product Platform Concept Exploration Method for Product Family Design”, Proceedings of DETC99 / ASME Design Engineering Technical Conferences, Las Vegas, September 12-15, 1998.

Stone, R., Wood, K. and Crawford, R. (2000), "A heuristic method for identifying modules for product architectures", Design Studies, Vol. 21 No. 1, pp. 5-31. https://doi.org/10.1016/S0142-694X(99)00003-4

Suh, E.S., De Weck, O.L. and Chang, D. (2007), "Flexible product platforms: framework and case study", Research in Engineering Design, Vol. 18 No. 2, pp. 67-89. https://doi.org/10.1007/s00163-007-0032-z

Ulrich, K. and Eppinger, S.D. (2004), Product Design and Development, McGraw-Hill/Irwin, New York.

Erik Greve, M.Sc.

Hamburg University of Technology, Institute of Product Development and Mechanical Engineering Design

Kletterrosenweg 24, 22177 Hamburg, Germany

Email: erik.greve@tuhh.de 